\title{
BIOETHICS UPdate
}

\section{The vaccines and the issue of public health emergencies}

\section{Las vacunas y el problema de las emergencias de salud pública}

Evandro Agazzi*

Editor in Chief, Bioethics UPdate journal, Mexico City, Mexico

Vaccines have finally arrived to help humanity fight the threat of coronavirus disease (COVID 19) and the mass media have presented this fact as a miracle of science as if, finally, the nightmare of the pandemic was now disappearing. In reality, the situation is much more complex and our journal had offered almost a premonition of this in the first issue of 2018, when this virus had not yet made its appearance in the world. In that issue, in fact, we published an article by David Shrader which dealt with the general theme of the need to rethink our bioethical approaches in the case of pandemic emergencies. Another article by Lourdes Velazquez offered a historical excursus on the devastating effects of smallpox epidemics on times when there were no vaccines against this disease. Apparently, they were two occasional writings, linked to the centenary of the famous epidemic of the so-called "Spanish" flu which in 1918 caused an estimated number of 50-100 million deaths worldwide, while the article by L. Velazquez highlighted the enormous consequences that uncontrollable contagion can have indiscriminately killing the citizens of a country, from the humblest to the emperor, and even causing the fall of an empire, as happened when a modest contingent of Spaniards led by Cortez conquered Mexico in the $16^{\text {th }}$ century.

As often happens, reflection on history helps to better understand current situations and their complexity. In particular, they help us today to assess the true reach of vaccines, which has been obscured by their presentation as a miracle of science. First of all, we are stimulated to a critical analysis of the complex factors that condition the preparation and use of therapeutic tools of any type (from drugs to hospital beds) and which concern, for example, the production and the reliability of drugs, their availability in sufficient quantities, the criteria for their use in cases of scarcity compared to actual needs, the training of specialized health personnel, and so on. We, thus, realize that this alleged miracle is actually the result of the research efforts of several dozen laboratories spread in many countries, supported by public and private funding, in a competition between large pharmaceutical companies that have invested considerable capital in view of large profits and that

Correspondence:

*Evandro Agazzi

E-mail: evandro.agazzi@gmail.com

CC BY-NC-ND (http://creativecommons.org/licenses/by-nc-nd/4.0/).

Date of reception: 15-02-2021

Date of acceptance: 16-02-2021

DOI: 10.24875 /BUP.M21000006
Disponible en internet: 21-05-202

BIOETHICS UPdate 2021;7(1):1-2 www.bioethicsupdate.com 
the race against time was not driven solely by the humanitarian urgency to save lives, but also by other reasons that may have reduced the rigor of testing and controls. Hence, without insinuating suspicion towards anyone, we feel the rational need to analyze the single knots of this network of conditions, which can give rise to legitimate doubts, highlight critical issues, and identify obstacles that can wholly or partially frustrate the realization of the miracle in many concrete situations. The awareness of the limited nature of the vaccine problem also falls within this critical consciousness, in the double sense that (i) even with respect to the goal of fighting the current pandemic, vaccines are not the absolute weapon that alone solves the problem but must be accompanied to measures of hygiene, protection, and social distancing that continue to apply; (ii) that the same fight against COVID-19 cannot have such a priority within the health facilities as to threaten the adequate treatment of many other pathologies. Furthermore, in this case, we are going to address these problems in our journal through the study of a concrete example (that of the vaccine against cervical papilloma) which will begin in this very issue.

The current pandemic has imposed lockdowns, isolations, suspensions of production activities, and job losses that have had enormous repercussions, causing the health crisis to generate also an economic crisis and a social crisis throughout the world. It is now known that, even in the best of hypotheses, the time needed to overcome the health crisis will be large and that, in any case, we will arrive at a situation, in which we will be forced to live with the coronavirus and beware of it, just because will have changed lifestyles, our behaviors and habits during the pandemic: it will not be a returning to so-called normality as before, but we will find ourselves living in a new world, not only more limited than the past in some aspects but also in other aspects enriched with other forms of activity and types of work to which the pandemic has forced us. We should, therefore, prepare ourselves for this new situation, but, unfortunately, it is a substantially unpredictable situation, precisely due to the complexity of the factors involved which, as specialists know, also entails the non-linearity of the processes and their unpredictability. However, it is not impossible to prepare for the new and the unknown even in these conditions: it is like when we have to reach a distant destination in a territory for which we do not have maps already drawn. Our resource can be a compass, which offers us an orientation, indicates a direction in which to move. In our case, it is a question of discovering some fundamental values and principles that can be recognized, received, and applied in a shared way by the greatest number of human communities and that allow the oppositions between needs and interests to be transformed into the search for compatibility. This is a task that cannot be asked of science and technology, but which is part of the specific vocation of what in the Western world we call philosophy, but which is present in all cultures as an aspiration to a wisdom that helps to confer a sense and a value to individual and collective existence and which scientists and technologists also need as human beings. For this reason, we will host two specific contributions by philosophers in the present issue of our journal.. 